\title{
Drug utilization study in patients of hypertension in tertiary care hospital
}

\author{
Prashant S. Mishra ${ }^{1 *}$, U. P. Gawali ${ }^{1}$, Salman H. Rizvi ${ }^{1}$, Sukhmeen Kaur ${ }^{2}$
}

${ }^{1}$ Department of Pharmacology, Dr VMGMC, Solapur, Maharashtra, India

${ }^{2}$ Department of Pharmacology, MGM Medical College, Aurangabad, Maharashtra, India

Received: 18 June 2020

Accepted: 14 July 2020

\section{*Correspondence:}

Dr. Prashant S. Mishra,

Email: drprashantm8@gmail.com

Copyright: (c) the author(s), publisher and licensee Medip Academy. This is an open-access article distributed under the terms of the Creative Commons Attribution Non-Commercial License, which permits unrestricted non-commercial use, distribution, and reproduction in any medium, provided the original work is properly cited.

\begin{abstract}
Background: Hypertension is the most common modifiable risk factor for cardiovascular diseases, stroke and renal failure. Drug utilization research facilitates the rational use of drugs and provides an insight into the pattern of drug use. As such, the present study was conducted to assess the prescribing patterns of antihypertensive agents and to observe the disparity between the recommended and actual practices for pharmacological management of hypertension at a tertiary care hospital.

Methods: A prospective, observational and cross-sectional study was conducted in Department of Pharmacology in collaboration with Department of Medicine in a tertiary healthcare hospital. As per inclusion criteria, patients with hypertension visiting Medicine OPD from 1st October 2018 to 31st December 2018 were enrolled in the study.

Results: A total of 390 prescriptions were collected. It was observed that majority of the study patients were female $(53.84 \%)$ and were $>60$ years of age. Average number of drugs prescribed per prescription was 4.18. Multiple drug regimen $(67.69 \%)$ was the mainstay therapy in our study. Prevalence of two drug combination was the highest (46.92\%) followed by monotherapy (32.3\%). Calcium channel blockers (CCBs) (amlodipine) was the most frequently prescribed class in monotherapy (19.23\%). In two drug regimens, the combination of CCB with angiotensinconverting enzyme inhibitors (ACEIs) (combination of amlodipine and enalapril) was prescribed the most (28.46\%) whereas prescription of combination of ACEI, beta-blocker (BB) and CCB (enalapril, atenolol and amlodipine combination) was the highest $(13.84 \%)$ in three drug regimens.

Conclusions: The prescription pattern of antihypertensive drugs was found to be rational and mainly in accordance with Joint National Committee VIII guidelines. All the drugs were prescribed by their generic names which suggests awareness among prescribers regarding WHO policies for generic prescribing.
\end{abstract}

Keywords: Prescription, Hypertension, Antihypertensive drugs, Polypharmacy

\section{INTRODUCTION}

Hypertension (HTN) is a major health problem worldwide causing significant morbidity and mortality. A large proportion of individuals are affected by it in both developed as well as developing nations. ${ }^{1,2}$ HTN is associated with an increased risk of various diseases such as myocardial infarction, heart failure, stroke, retinopathy and renal failure. ${ }^{3.4}$ Elevated blood pressure (BP) is responsible for nearly 7.5 million deaths or $12.8 \%$ of the total annual deaths globally. ${ }^{5}$ According to the World Health Organization (WHO) estimates, 1.5 million people are predicted to be hypertensive by $2025 .^{6}$ In Indian scenario, the prevalence of HTN is increasing at an alarming rate. ${ }^{7,8}$ Through a cross-sectional, population 
based study, the overall Indian prevalence of HTN was found to be $25.3 \% .^{9}$

The main aim of anti-hypertensive therapy was to reduce morbidity and mortality associated with HTN. ${ }^{10}$ Clinically it has been evident that, the use of antihypertensive therapy significantly reduces the risk of various HTN associated complications. ${ }^{11}$ Several classes of drugs such as diuretics, beta-blockers (BBs), angiotensin-converting enzyme inhibitors (ACEIs), angiotensin receptor blockers (ARBs), and calcium channel blockers (CCBs) are prescribed alone or in combination for the treatment of HTN. ${ }^{10,12}$ For management of HTN, various guidelines are available such as American Society of Hypertension/ International Society of hypertension (ASH/ISH), Joint National Committee (JNC), (ESH)/European Society of Cardiology (ESC), National Institute for Health and Care Excellence (NICE) and Japanese Society of Hypertension guidelines. ${ }^{13}$ Among these, JNC VIII guidelines (published in 2014) are considered as the "gold standard". ${ }^{11}$

Choice of an appropriate anti-hypertensive drug depends on various factors like age of patient, underlying comorbid conditions, efficacy and safety of drug and cost of drug. ${ }^{11,12}$ In 1977, drug utilization research was defined by WHO as "the marketing, distribution, prescription and use of drugs in a society, with special emphasis on the resulting medical, social, and economic consequences". ${ }^{14}$ Drug utilization research is an essential tool to facilitate the rational use of drugs and provides an insight into the pattern of drug use. ${ }^{14}$ As such, it is necessary to emphasize appropriate methods for auditing drug therapy towards rationality. ${ }^{15}$ Keeping this in mind, this study was planned to evaluate the current trends in prescription of antihypertensive drugs in a tertiary care hospital.

\section{METHODS}

This prospective and observational study was carried out in department of pharmacology in collaboration with department of medicine of a tertiary healthcare teaching institute in Maharashtra after obtaining approval from the institutional ethics committee. Patients were given prior information.

\section{Study design}

It was a hospital based prospective, cross-sectional and observational study.

\section{Study period}

The study was conducted over a period of 3 months from $1^{\text {st }}$ October 2018 to $31^{\text {st }}$ December 2018 at a tertiary care teaching institute in Maharashtra.

\section{Sampling}

A total of 390 prescriptions were selected.

\section{Inclusion criteria}

All patients of either sex and above the age of 18 years visiting HTN OPD during the above-mentioned study duration were enrolled in the study.

\section{Exclusion criteria}

Patients below the age of 18 years, those unwilling to participate in the study and all IPD patients.

\section{Methodology}

The following data was collected and analysed i.e. demographic information: age and sex; diagnosis; antihypertensive drugs categorized into different classes, their doses, frequency and dosage form; prevalence of polypharmacy.

Data was entered and analysed using Microsoft Excel 2013.

\section{RESULTS}

During the study period, a total of 390 prescriptions of hypertensive patients were collected. It was observed that in our study, there was female predominance $(53.84 \%)$ where as $46.15 \%$ prescriptions were of males. Figure 1 shows the age and gender wise distribution of HTN in patients. Maximum study participants were $>60$ years of age in which $144(36.92 \%)$ were males and $159(40.76 \%)$ were females. In the age group of 46-60 years, $24(6.15 \%)$ were males and $42(10.76 \%)$ were females. Also, 12 $(3.07 \%)$ male cases and $9(2.3 \%)$ female cases were observed in the age group of 31-45 years. However, no case of HTN was reported in the age group of 18-30 years. Type II diabetes was the only comorbidity observed in $72(18.46 \%)$ patients.

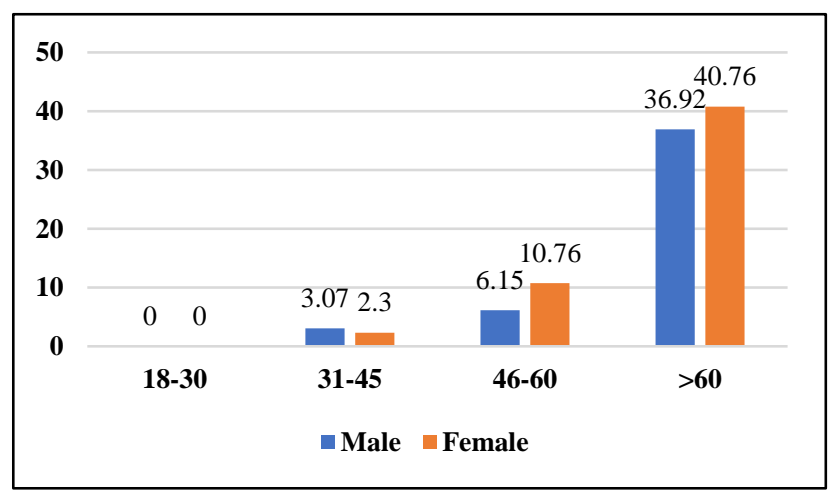

Figure 1: Age and gender wise distribution of patients.

A total of 1632 drugs were prescribed for 390 patients of which $744(45.58 \%)$ were antihypertensives and remaining $888(54.41 \%)$ were multivitamins, oral hypoglycaemics and other concomitant drugs. All the drugs were prescribed by generic names. Average number of drugs prescribed per prescription was 4.18 . 
Table 1: Prescribed anti-hypertensive drugs (monotherapy and combinations).

\begin{tabular}{|c|c|c|c|}
\hline $\begin{array}{l}\text { Class of antihypertensive } \\
\text { drug }\end{array}$ & Generic name of drug & $\begin{array}{l}\text { No. of } \\
\text { patients }\end{array}$ & $\begin{array}{l}\text { Percentage } \\
(\%)\end{array}$ \\
\hline Monotherapy & & 126 & 32.3 \\
\hline BB & Atenolol & 6 & 1.53 \\
\hline CCB & Amlodipine & 75 & 19.23 \\
\hline ACEI & Enalapril & 45 & 11.53 \\
\hline Two drug regimen & & 183 & 46.92 \\
\hline $\mathrm{CCB}+\mathrm{ACEI}$ & Amlodipine+enalapril & 111 & 28.46 \\
\hline $\mathrm{BB}+\mathrm{CCB}$ & Atenolol+amlodipine & 24 & 6.15 \\
\hline ACEI+diuretic & Enalapril+furosemide & 15 & 3.84 \\
\hline $\mathrm{CCB}+$ diuretic & Amlodipine+furosemide & 9 & 2.3 \\
\hline $\mathrm{BB}+\mathrm{ACEI}$ & Atenolol+enalapril & 24 & 6.15 \\
\hline Three drug regimen & & 75 & 19.23 \\
\hline $\mathrm{BB}+\mathrm{CCB}+$ diuretic & Atenolol+amlodipine+furosemide & 3 & 0.76 \\
\hline $\mathrm{ACEI}+\mathrm{BB}+\mathrm{CCB}$ & Enalapril+atenolol+amlodipine & 54 & 13.84 \\
\hline $\mathrm{BB}+\mathrm{ACEI}+$ diuretic & Atenolol+enalapril+furosemide & 9 & 2.3 \\
\hline $\mathrm{ACEI}+\mathrm{CCB}+$ diuretic & Enalapril+amlodipine+furosemide & 9 & 2.3 \\
\hline Four drug regimen & & 6 & 1.53 \\
\hline $\mathrm{ACEI}+\mathrm{BB}+\mathrm{CCB}+$ diuretic & Enalapril+amlodipine+furosemide & 3 & 0.76 \\
\hline $\mathrm{ACEI}+\mathrm{BB}+$ diuretic+diuretic & Enalapril+atenolol+furosemide+spironolactone & 3 & 0.76 \\
\hline Total & & 390 & 100 \\
\hline
\end{tabular}

BB: Beta Blocker, CCB: Calcium Channel Blocker, ACEI: Angiotensin converting enzyme inhibitors

Only $32.3 \%$ patients received single antihypertensive drug whereas most of the hypertensive patients were on multiple drug therapy $(67.69 \%)$. The results revealed that prevalence of two drug regimen was the highest $(46.92 \%)$ followed by monotherapy $(32.3 \%)$. Three drug regimens were prescribed in $19.23 \%$ patients whereas only $1.53 \%$ patients received four drug regimens as shown in Table 1.

Among the monotherapy, the most frequently prescribed class was CCBs (amlodipine) for 75 patients (19.23\%) followed by ACEIs (enalapril) for 45 patients (11.53\%). Only 6 patients $(1.53 \%)$ received $\mathrm{BBs}$ (atenolol) (Table 1).

In our study, five different two drug combinations of antihypertensive drugs were prescribed among which the combination of CCB with ACEI (amlodipine + enalapril) was prescribed the most $(28.46 \%)$. The utilization of other two drug combinations was comparatively less (Table 1).

In three drug combinations, prescription of combination of ACEI, beta blocker and CCB (enalapril, atenolol and amlodipine combination) was the highest (13.84\%). However, only 6 patients $(1.43 \%)$ received combination of four anti-hypertensive drugs (Table 1).

\section{DISCUSSION}

Monitoring of prescription pattern is an essential tool to promote rational use of drugs and minimise their abuse or misuse. It creates awareness among prescribers as well as general public about appropriate usage of drugs, their quality, prescription trends and ensures compliance with standard treatment guidelines. ${ }^{15,16}$

In our present study, total 390 prescriptions in hypertension OPD were evaluated. It was observed that maximum number of patients were above 60 years of age. It is a well-established fact that BP increases steadily with age, which accounts for increased prevalence of HTN among older individuals. ${ }^{17,18}$ This can be attributed to age related stiffening of blood vessels, reduction of baroreflex sensitivity, change in balance between $\beta$-adrenergic vasodilatation and $\alpha$-adrenergic vasoconstriction, and limited renal ability to excrete sodium overload. ${ }^{18.19}$

The present study observed that majority of the study population was female $(53.84 \%)$. Similar trend was reported in studies by Abegaz et al and Gupta et al. ${ }^{20,21}$ However, the above pattern is anomalous to other studies conducted by Jhaj et al and Murty et al that reported higher prevalence of HTN in males. ${ }^{22,23}$ Out of 390 patients, comorbidity (type II diabetes mellitus) was observed only in $72(18.46 \%)$ patients. Similarly, diabetes mellitus was reported as the most frequent co-morbidity in a study by Sakthi et al. ${ }^{24}$

The results of our present study showed that average number of drugs prescribed per prescription was 4.18 and all the drugs were prescribed by generic names. Similar trend was observed in a study conducted in rural areas of Kerala by Ramadas et al that reported 4.19 as average 
number of drugs per prescription. ${ }^{25}$ Maximum number of patients received multiple drug therapy (67.69\%) which are comparable to findings in studies by Abegaz et al and Gupta et al that showed adequate management of HTN by utilising combination therapy. ${ }^{20,26}$ It was observed that CCBs $(19.23 \%)$ was the most commonly prescribed antihypertensive agent as monotherapy. Amlodipine was the only drug prescribed from this class in this study. Use of CCBs as monotherapy is in accordance with previous studies conducted by Konwar et al and Mishra et al. ${ }^{27,28}$ Diuretics were not used as monotherapy and were preferred only in combination therapy. Adverse effect profile of diuretics on glucose homeostasis and lipid profile might be responsible for underutilisation of diuretics. ${ }^{29}$ According to JNC VIII guidelines, BBs should not be used as first line therapy. ${ }^{11}$ In spite of this, $1.53 \%$ patients in our study received atenolol as monotherapy.

In our present study, it was also observed that in combination therapy, two drug combination was preferred accounting for $46.92 \%$ prescriptions. Our findings are consistent with a study conducted by Gupta et al that observed more prevalence of dual antihypertensive therapy (41.9\%). ${ }^{26}$ Among the two drug combinations, the most prescribed combination was of CCB with ACEI (amlodipine+enalapril) (28.46\%). JNCVIII guidelines advocate the use of ACEIs, ARBs, thiazide diuretics, and CCBs as monotherapy or in combination for the management of early stage HTN. ${ }^{11}$ Hence, results of our study support adherence to JNCVIII guidelines.

It was observed that $19.23 \%$ patients were prescribed three drug combinations in our present study. Among them, prescription of $\mathrm{ACEI}+\mathrm{BB}+\mathrm{CCB}$ was the highest $(13.84 \%)$ as seen in a study by Sikider et al. ${ }^{30}$ However, several studies in the past reported the combination of $\mathrm{ARB} / \mathrm{ACEI}, \mathrm{CCB}$ and diuretics as the most preferred three drug combination. ${ }^{31-33}$

\section{CONCLUSION}

This study provides an overview on utilization of antihypertensives in one of the tertiary care hospitals in Maharashtra. In this study, the overall analysis of prescription pattern suggests rationality in prescription practices in selection of suitable antihypertensive drugs and adherence to JNC VIII guidelines. Moreover, all the drugs were prescribed by generic names which advocates awareness among prescribers regarding WHO policies for generic prescribing. However, shorter duration and small sample size are some of the limitations of our present study. As such, more systematic studies are required in a developing country like India to evaluate drug utilization pattern of antihypertensive drugs that can cater individual needs of patients.

Funding: No funding sources Conflict of interest: None declared

Ethical approval: The study was approved by the Institutional Ethics Committee

\section{REFERENCES}

1. Kearney PM, Whelton M, Reynolds K, Whelton PK, He J. Worldwide prevalence of hypertension:a systematic review. J Hypertension. 2004;22(1):11-9.

2. Akunne OO, Adedapo ADA. Antihypertensive prescription among black patients without compelling indications: prescription, effectiveness, quality and cost of medication. BMC Health Serv Res. 2019;19(1):373.

3. Shah SJ, Stafford RS. Current Trends of Hypertension Treatment in the United States. Am J Hypertens. 2017;30(10):1008-14.

4. Adejumo O, Okaka E, Iyawe I. Prescription pattern of antihypertensive medications and blood pressure control among hypertensive outpatients at the University of Benin Teaching Hospital in Benin City, Nigeria. Malawi Med J. 2017;29(2):113-7.

5. Mendis S. World Health Organisation;2010. Global status report on non-communicable diseases 2010. Available at: http://www.who.int/nmh/publications/ ncd_report2010/en/. Accessed on 03 March 2020.

6. Kearney PM, Whelton M, Reynolds K, Muntner P, Whelton PK, He J. Global burden of hypertension:Analysis of worldwide data. Lancet. 2005;365:217-23.

7. Mittal P, Mittal Y. Prevalence of hypertension among rural population of Doiwala block, Dehradun. Recent Res Sci Technol. 2013;5:21-4.

8. Jose AP, Prabhakaran D. World Hypertension Day:Contemporary issues faced in India. Indian $\mathbf{J}$ Med Res. 2019;149:567-70.

9. Geldsetzer P, Manne-Goehler J, Theilmann M, Davies JI, Awasthi A, Vollmer S, et al. Diabetes and hypertension in India:A nationally representative study of 1.3 million adults. JAMA Intern Med. 2018;178:363-72.

10. Rimoy GH, Justin Temu M, Nilay C. Prescribing patterns and cost of antihypertensive drugs in private hospitals in Dar es Salaam. East Cent Afr J Pharm Sci. 2008;11:69-73.

11. James PA, Oparil S, Carter BL, Eighth Joint National Committee (JNC 8) Members, et al. 2014 evidencebased guideline for the management of high blood pressure in adults:report from the panel members appointed to the Eighth Joint National Committee(JNC 8), Supplemental Content. JAMA. 2014;311:507-20.

12. Rang HP, Dale MM, Ritter JM, Flower RJ, editors. The vascular system. In: Rang and Dale's Pharmacology. 6th Edition. UK: Churchill Livingstone; 2007: 298-320.

13. Jarari N, Rao N, Peela JR. A review on prescribing patterns of antihypertensive drugs. Clin Hypertens. 2016;22:7.

14. WHO. What is drug utilization research and why it is needed? In:Introduction to Drug Utilization Research-World Health Organization; 2003: 8-12. Available at http://apps.who.int/medicinedocs/ pdf/s4876e/s4876e. pdf. Accessed on 03 March 2020. 
15. Introduction to Drug Utilization Research. Oslo, Norway. WHO; 2003: 1-73.

16. Strom BL, Stephan EK, editors. Pharmacoepidemiology. 4th ed. Wiley-Blackwell: John Wiley and Sons, English; 2005.

17. Lewington S, Clarke R, Qizilbash N, Peto R, Collins R. Age-specific relevance of usual blood pressure to vascular mortality:a meta-analysis of individual data for one million adults in 61 prospective studies. Lancet. 2002;360(9349):1903-13.

18. Anker D, Santos-Eggimann B, Santschi V, Giovane CD, Wolfson C, Streit S, et al. Screening and treatment of hypertension in older adults: less is more? Public Health Rev. 2018;39:26.

19. Pinto E. Blood pressure and aging. Postgrad Med J. 2007;83(976):109-14.

20. Abegaz TM, Tefera YG, Abebe TB. Antihypertensive drug prescription patterns and their impact on outcome of blood pressure in Ethiopia:a hospital-based cross-sectional study. Integr Pharm Res Pract. 2017;6:29-35.

21. Gupta SK, Nayak RP, Rahavi R, Kumar A. A crosssectional retrospective study to assess the pattern of prescribing for inpatient hypertensive cases in a tertiary hospital and to find out the possible avenues for betterment of hypertension management. Arch Med Health Sci. 2015;3:60-5.

22. Jhaj R, Goel NK, Gautam CS, Hota D, Sangeeta B, et al. Prescribing patterns and cost of antihypertensive drugs in an internal medicine clinic. Ind Heart $\mathrm{J}$. 2001;53:323-7.

23. Murti K, Khan MA, Dey A, Sethi MK, Das P, Pandey K. Prescription Pattern of Anti-Hypertensive Drugs in Adherence to JNC- 7 Guidelines. Am J Pharmacol Toxicol. 2015;10(1):27-31.

24. Sakthi S, Thomas S, Sivakumar KK, Karhikeyan J, Saravana Kumar N. Assessment of anti-hypertensive prescribing pattern and patient counseling in an urban population. Der Pharmacia Lettre. 2010;2(4):156-63.

25. Ramadas S, Sujatha MB, Andrews MA, Sanalkumar K. B. Drug utilization study of antihypertensive drugs and prevalence of blood pressure control in adult hypertensive patients based on JNC VIII guidelines in a tertiary care hospital: a cross sectional study. Int J Basic Clin Pharmacol. 2019;8:245-52.

26. Gupta R, Malhotra A, Malhotra P. Study of prescribing pattern of drugs used in the treatment of hypertension in a tertiary care teaching hospital in North India:an observational study. Int J Res Med Sci. 2018;6:2380-4.

27. Konwar M, Paul PK, Das S. Prescribing pattern of antihypertensive drugs in essential hypertension in medicine out patients department in a tertiary care hospital. Asian J Pharm Clin Res. 2014;7(2):142-4.

28. Mishra R, Kesarwani P, Keshari SS. Prescription pattern of antihypertensive drugs in a tertiary care teaching hospital. Int $\mathbf{J}$ Med Sci Public Health. 2017;6(4):684-6.

29. Prisant LM, Beall SP, Nicholads GE, Feldman EB, Carr AA, Feldman DS. Biochemical, endocrine, and mineral effects of indapamide in black women. J Clin Pharmacol. 1990;30:121-6.

30. Sikidar P, Chakravarty P, Purkayastha A, Tigga R. A study on prescribing pattern of antihypertensives in adult patients attending in a tertiary care hospital of Assam, India. Int J Basic Clin Pharmacol. 2016;5:975-8.

31. Sharma AK, Dahiya N, Kairi JK, Bharati SM. Hypertension: prescription audit in a tertiary care hospital in India. Int $\mathrm{J}$ Basic Clin Pharmacol. 2015;4:55-9.

32. Sivakumar A, Venkateswaramurthy N, Sambathkumar R. Study of drug prescription pattern of anti-hypertensives in a tertiary care hospital. Der Pharmacia Lettre, 2014;6(4):86-8.

33. Varghese GM, Imran Md, Gara P, Tom C, Suresh V, Nanjvade BK. Study on drug utilization pattern of antihypertensive agents in a tertiary care hospital. World J Pharm Pharma Sci. 2016;5:1078-89.

Cite this article as: Mishra PS, Gawali UP, Rizvi SH, Kaur S. Drug utilization study in patients of hypertension in tertiary care hospital. Int J Basic Clin Pharmacol 2020;9:1275-9. 